\title{
WELL-BEING AS CONCEPT IN PSYCHOLOGY OF LATVIA
}

\author{
Guna Svence \\ Riga Teacher Training and Education Management Academy, Latvia \\ E-mail: guna.svence@rpiva.lv
}

\begin{abstract}
The aim of the research is to analyze the psychological problems of the new generation in Latvia at the present moment. The currently existing psychological issues are inherited from the 20s and 30s of the previous century. In Latvia the topicality in the field of psychology has always been associated with a sound development of a physically-fitted, mentally-balanced as well as meaningful personality that might benefit society. Latvian psychological theories are based on the humanistic and philosophical approach that is based on the human ideas from the 90ies of $20^{\text {th }}$ century. Such Latvian psychologists as Imants Plotnieks, Arija Karpova, Dzidra Meik ane and others researched the following topics: 'self-esteem', 'self-regulation ", 'self-actualization ", "identity" as well as "positive self-concept".

The scientific issue of this article is to compare and to analyze the two dimensions of the Latvian psychology history, i.e., firstly, what it is based on and, secondly, why the reason of a positive psychology concept is rooted in Latvian traditions.

The methodology of the research is meta-analysis, qualitative-quantitative approach, and experimental design from three cases analyse.

There are three cases analysed in this article- author of this article and students from Riga Teacher Training and Education management academy, all cases analysed well-being aspect resilience and positive intervention, but there is different aspect of resilience has been analysed in each example.

There are some similar ideas from Latvian psychology history are comparing with temporary psychology of Latvia in this article, ideas - close and different with positive psychology as methodological branch of psychology.
\end{abstract}

Key words: Latvian psychology history, optimism, well-being, resilience.

\section{Introduction}

The main focus of this article is question- what are the common features between the Latvian psychology in $21^{\text {st }}$ century and Latvian psychology in the $20 \mathrm{~s}, 30 \mathrm{~s}$ as well as the $90 \mathrm{~s}$ of $20^{\text {th }}$ century? Purpose of this article is to study the connection between the fundamental ideas about the positive psychology concept underlying the Latvian psychology and that of other countries in the 20s, 30s and $90 \mathrm{~s}$ of $20^{\text {th }}$ century and $2000 \mathrm{~s}$ of $21^{\text {st }}$ century according to the following criteria: similarities between the definitions of the personality aspects in the content of the hypothesis on personality and its development. The other purpose is to compare some cases from researches about positive psychology today what are made in Latvia at Riga Teacher Training and Education management academy 
What is positive psychology and could it been compared with history of Latvian psychology?

One of the main similarities is the interconnection with the well-being of the personality and society. The well- being as a concept of positive psychology since $90 \mathrm{~s}$ of $20^{\text {st }}$ century is associated with positive thinking, happiness, resilience, meaningfulness, optimism, achievements, choice, love, joy, play, flow as well as creativity that are based on the humanistic approach of science. It should be stressed that the Latvian science of psychology is chiefly shaped on the basis of philosophy and sociology. Therefore, a lot of authors in psychology studies are philosophers, pedagogues, and sociologists (for instance, Pauls Dale (Pauls Dāle), Pauls Jurevics (Pauls Jurevičs), Julijs Aleksandrs Students (Jūlijs Aleksandrs Students), Milda Liepina (Milda Liepina)). In the 20s, 30s literature and research works the development of Latvian awareness was caused by national patriotism, thus, psychology was one of the scientific disciplines supported by the state.

In Soviet times the only researcher who worked on summarizing and analyzing the history of Latvian psychology was I. Plotnieks, however, he passed away before finishing it. That is why lecturers (G. Svence, R. Bebre, A. Lasmane, D. Berzina and students (G. Klavina (G. Kļavinga), G. Actina, I. Eveliete, R. Akermane, I. Peholca, I. Kreslina etc.) of the Riga Teacher Training and Education Management Academy carried out their research grounded on historically-explored concepts. The first book about the Latvian psychology history was published in 2009. And this fact is connected with another new subject, i.e., positive psychology that appeared as a new subject in Latvian psychology in 2009 , too.

Why are both subjects interconnected according to the author's view of the research work?

Latvians as a nation have a mentality quality to keep inner resilience and optimism during different historical circumstances, for instance, after the $1^{\text {st }}$ World War, when the national independence was gained, and after the fall of the Soviet regime, when the nation restarted to build a new state in an optimistic way, and after the economic crisis in 2007, when the nation lost trust and thousands of Latvians left their Fatherland, a great number of psychologists, philosophers as well as anthropologists restarted to work with meaningfulness, with optimism and with great trust as well.

Why it is actual to research positive psychology in Latvia?

What was topical in the history of psychology of Latvia in the previous century? What features are typical in psychology of Latvia today? What is associated with the idea of positive thinking as a national concept of psychology in Latvia?

In Latvia the 1920s and 30s are considered to be the birth of psychology as a scientific branch. Latvia gained its independence in 1918. Alongside with the science and culture boom, Latvia experienced a growth of interest in the understanding of the life of the soul from a scientific perspective. It is essential to realize that the authors of the history of Latvian psychology, who focused on psychology research, made a link with European psychologists (Carl Gustav Jung, Sigmund Freud, Wilhelm Wundt, Alfred Adler etc.). At the dawn of the history of Latvian psychology the same questions were asked as at the beginning of the history of the world psychology: what is psyche, how human emotions, mind, creative thoughts manifest themselves within the external and internal reality in this world depending on individual traits, age as well as gender.

Before the Latvian state gained its independence, Latvians could acquire academic education only at the University of Terbata, in St Petersburg and Moscow. In the years of independence there was a chance to study at the University of Latvia and at private universities as well.

Exploring the works of the authors of the history of Latvian psychology of the 20s, 30s, it can be stated that the development of psychology in Latvia is connected with philosophy, literature, ethics, mythology, and Latvian wisdom of life (Z. Maurina (Z. Maurina), P. Birkerts), for instance, the analysis of a human in Latvian folksongs (Latvju tautas dainas). In fact, Latvian folksongs are the first source of human psychology. J. Bunduls' writings also show the close connection between philosophy and psychologic - philosophical terms, references of philosophers' quotes. The same refers to J.A. 
OF PSYCHOLOGY

IN THE $21^{\text {st }}$ CENTURY Volume 2, 2012

56

Students' writings that also highlight philosophers' insights. Peteris Zalite (Pèteris Zālìte) wrote the work 'The Soul of the Latvian People' ('Latviešu tautas dvēsele') (1923) emphasizing the need of the Latvian people for self-determination, freedom, and inner purity (baltā dvēsele - white soul).

The science of psychology in Latvia is closely connected with pedagogy, biology, medicine and sociology etc. likewise all around the world. According to the psychologist J.A. Students: 'Sciences with a common study subject might elucidate their object more closely because in such a case science derives from the other science the thing it lacks and the thing that clarifies the study process as well as the object.' Also, J.A. Students voiced the idea of the interaction among various branches of science.

The research of the history of Latvian psychology revealed that P. Birkerts, a remarkable Latvian psychologist of the 20s and 30s, introduced a sub-branch of psychology in Latvia that is called worldwide 'the psychology of the artistic creation' and thereby was the first one to introduce the concept of creation (dail radǐšana). It means that Latvian psychologists have also made a global contribution since there was no sub-branch like that ever before.

One of the most distinguished psychologists of the time was J.A. Students (1898-1964) who is notable for his contribution to the research of personality development and the development of this sub-branch in Latvia as well.

In the 20 s as well as 40 s a considerable contribution to the history of Latvian psychology was also made by J. Bunduls and P. Dale; they examined the personality by analyzing lives of famous people and interpreting their achievements. Writings of J. Bunduls and P. Dale are characterized by the influence of philosophy since many mental processes are contemplated from a philosophical aspect. Their interpretations of the sub-branches of psychology are mainly based on their reflections without substantiation from the empirical research or references to insights and studies of other globally recognized psychologists, thus, we may say that one of the key methods used in the history of Latvian psychology was introspection. In 1921 a monographic study 'The Human Soul and The Central Nervous System' ('Cilvēka dvēsele un centrālā nervu sistēma') by Pauls Dale was published; it focused on the independence of pure introspective psychology, substantial unity and creative activity of the soul and its dynamic contact with flesh.

In general, the division of sub-branches of psychology in the 20s-40s was different from what we have today, for instance, psychology of love, psychology of thinking, psychology of volition, psychology of feelings, character psychology were classified as individual sub-branches. Nowadays many of these sub-branches have been placed under personality psychology, psychology of emotions, cognitive psychology etc. In the 20 s and 30 s there was no such sub-branch as cognitive psychology in Latvia because the term and the sub-branch of psychology did not exist yet. In his writings J.A. Students called the present cognitive psychology the 'psychology of thinking' and within the framework of this discipline he looked at all processes that are nowadays called 'cognitive processes' and researched as well as analyzed them by cognitive psychology in detail. However, it should be pointed out that the other Latvian authors used the term psychology of intelligence meaning cognitive psychology. Teodors Celms was eager to analyze the cognitive sphere and certain processes of attention, for example, he analyzed and described the nature of the personality. A certain contribution to the study of the cognitive sphere was also made by psychologist J. Silins (J. Siliňs ) who focused on the psychology of feelings, however, in terms of the personality development he focused on the development of the will. The conclusions are based on the analyzed theoretical research material in the 20s-40s,i.e., the topical sub-branches were cognitive psychology, psychology of artistic creation, psychology of love, psychology of volition as well as psychology of education or pedagogical psychology.

Due to the pedagogical policy of the state at that time, researchers particularly focused on the youth, youth development, and their career choice. For example, a career advisory centre was established aimed at examining and determining the most appropriate occupation for each individual further education. In the 20s-30s P. Dale set up a Laboratory of Experimental Psychology in Latvia; later on, it was transformed into an institution conducting the first empiric studies.

Our historic view of the Latvian psychology in the 20-30s is connected with trust and resilience, optimism of the personality development that is closely linked with the current topicality in psychology of Latvia. 
Topicality of Latvian psychology today is positive psychology, and the main topics are positive thinking, resilience, strengths of personality, creative thinking and developmental methodology.

The first dissertation of positive psychology related to the humanistic approach in the developmental psychology was the dissertation of the author of this work; it was based on the correlation of positive communication and self-esteem among school pupils and teachers. Likewise in the past we can find the same issue in the temporary psychology of Latvia, i.e., our base is pedagogy and communication models from humanistic philosophy.

Today psychology is studied in different Latvian higher education institutions: Latvian University, Riga Teacher Training and Education Management Academy, the University of Daugavpils etc., but positive psychology as the main subject of research has been created in the Riga Teacher Training and Educational Management Academy.

How it is possible with such a pessimistic background to focus on positive psychology?

The Latvian National Developmental Plan within the period of 2007 to 2013 intends to launch the implementation of the objective, i.e., to increase the quality of life of the population with a mission to approach the average level of EU-25. Within the Plan a number of interrelated aspects, determining the quality of life, to be more exact, the patterns of welfare, security and sustainable development have been worked out. Overall there were raised 28 aspects, such as awareness, education, innovation, employment, material welfare; psychological well-being, unfortunately, is not listed as a separate aspect, but it appears in the point of "participation", which clarifies that "an individual's psychological well-being is closely related to the participation and decision-making, membership in non-governmental organizations, public and private partnerships." In any case, within the framework of those plans in 2005 a research was carried out on "The quality of life in Latvia" in order to gain a complex insight into the problems and trends of the quality of life. The research outlined the economic situation, employment/ unemployment, education, family, housing, health, social participation, work and leisure time allocation as the key indicators of the quality of life in the perception of Latvians; the indicators that basically determine subjective indicators, i.e., happiness, satisfaction with life in general and specific areas of life. Within the research, a survey was carried out based on the opinion poll; one of the questions was: How satisfied or dissatisfied are you with your current life in general? The answers showed the subjective quality of the quality life indicator in Latvia. In 10-point scale, the indicator, according to the survey data, was 6.1, which shows a positive growth if compared with 2003 when the indicator was 5.5. Also, public opinion polls on the quality of life prior aspects and activities how to improve it are carried out on a regular basis. These surveys clearly show that the prior aspects that are essential to the quality of life of the Latvian population are material welfare, employment, health care, social welfare, physical security and education. It must be admitted, this result is in accordance with A. Maslow's theory; it means the survey results in Latvia clearly outline the situation that reveals the national concern about the satisfaction of the basic needs; moreover, it means that as long as people do not get sufficient remuneration and feel insecure, spiritual values such as culture, personality growth and self-actualization will never ever be forwarded as the most essential aspects of improving the quality of life. Despite these figures, I believe that they are incomplete and that this situation is temporary in Latvia, therefore further research should be continued to explore the subjective well-being of the population, as well as to develop appropriate teaching/ learning methods as well as ways how to achieve positive goals, how to become more satisfied with the standard of life in all age groups.

The data published in mass media in 2011 reveal that the living standards have dropped, and currently, in the circumstances of the ongoing economic crises the assessment of the quality of life has sharply decreased, evidenced not only in polls but also by Latvian Census in 2011, which shows that, compared with 90 s, the number of Latvian population has decreased by 500, 000; the majority of them are economic refugees who have moved to other countries to seek for employment.

As evidenced by the author's observations, conducting lectures in all major Latvian regional municipalities and educational institutions, people who are active, who learn and work, and not hopeless at all; they are eager to see more positive information in the content of education and mass 
OF PSYCHOLOGY

IN THE $21^{\text {st }}$ CENTURY Volume 2, 2012

58

media; also, there is an increasing demand for a sound educational content that would accentuate the skills of thinking positively, reduce the pessimistic thinking and increase resilience. Therefore, the Riga Teacher Training and Educational Management Academy researchers' team under the guidance of G. Svence over the last 4 years have carried out a number of studies in positive psychology.

In this article several examples of the recently carried out research within the period of 20112012 are mentioned. The examples of the research deal with the new concept in psychology such as resilience, well-being and optimism. The Latvian researchers' team (Svence, Golde, Majors, Majore, Pumpuriņa, Bērziña, Štāla within the period of 2010-2012) have successfully adapted concepts of well-being, optimism, positive thinking, resilience as well as positive intervention in Latvian psychology.

\section{Methodology of Research}

The research is based on a qualitative-quantitative approach, theoretical meta-analysis and experimental design.

Positive Psychology is a branch of psychology which explores human resources and skills that help to lead a meaningful and fulfilling life, rather than explore human disorders. The sense of security about the past, present and future is one of the prerequisites for a complete happiness.

The aim of positive psychology is to understand and to identify individual abilities, so that individuals, families and communities could thrive. Things that ensure people to experience great happiness, wisdom, psychological, physical and social well-being, are the same forces that work against physical and mental diseases. Free time is central in positive psychology and in helping individuals and society to realize their highest potential (Seligman \& Csikszentmihalyi, 2000).

Positive psychology has many remarkable ancestors. Since Socrates, Plato and Aristotle's times "good life" has been the subject of psychological and religious researches. It is exciting to mention psychologists have been working for decades on the positive psychology branch, but it was simply not known as positive psychology!

Some of them are such reputed authors as, for example:

- C.Rogers (1951), A.Maslow (1970), E.Fromm who are inventors of the humanistic psychology branch;

- creators of the base for well-being prevention programs - Albee (1982), Cowen (1994), Bandura (1989), Winner (2000);

- creators of a clear theory of intelligence - Gardner, (1983); Sternberg, (1985);

- Marie Jahoda (1958) developed the theory of Ideal Mental Health.

The history of the experimental research on happiness is relatively recent. Around 1960s American research organizations started interviewing people about happiness and satisfaction. Researches on happiness carried out in 1960s became popular in various areas. In gerontology happiness was the part of the notions of 'successful' aging, in epidemiology the concept of happiness was applied as the indicator of 'positive mental health', whereas sociology develops the concept of happiness as a 'social indicator'.

Reviewing positive psychology in the recent past, the psychologist Veenhoven should be mentioned who contributed significantly to positive psychology research, by issuing "Correlates of Happiness" in 1994, where he re-analyzed 630 most substantial studies from around the world. Such work as "Well-Being: Foundations of Hedonic Psychology" (Kahneman, Diener, \& Scwarz, 1999) should be mentioned as well because it includes a chapter on happiness researches carried out by M. Argyle.

In 1999 'Journal of Happiness Research' was issued, edited by the above mentioned Veenhoven. Also, scientific articles and research on positive psychology and happiness can be found in journals "Social Indicators Research" in 1974, 'Personality and Social Psychology" and in the publication 'Personality and Individual Differences'.

Currently the list of researchers on this sub-branch contains Donald Clifton, Albert Bandura, Martin Seligman, Ed Diener, Mihaly Csikszentmihalyi, C.R. Snyder, Christopher Peterson, Shelley 
Taylor, Barbara Fredrickson, Charles S. Carver, Michael F. Scheier and Jonathan Haidt.

Positive psychology representatives (Seligman et al, 2006) are aware that happiness is a subjective category, because everyone has their own idea of happiness and it is impossible to measure it. Therefore, positive psychology representatives are looking for objective criteria, which would not be mutually contradictory.

Seligman (2004) believes that positive psychology is the science that studies optimal human functioning. Its task is to understand and to evolve human capabilities that help them and the society to develop. Positive psychology focuses on strengths rather than weaknesses, asserting that happiness is not a mere result of good genes and luck.

The three main research areas of positive psychology are:

- positive experience;

- positive individual attitude;

- society and institutions.

- Research objects of positive psychology are:

- schools and families that promote children's development;

- workplaces that provide job satisfaction and high productivity;

- environment at work, at home and in public places fosters civic consciousness.

- Seligman (2004) defines happiness in two ways, -

- positive emotions that are connected with the feeling of comfort;

- activities that are connected with enjoyment.

Analyzing the Seligman's theory of positive psychology, the most important pre-condition for happiness is optimism. He maintains that the focus should be on human internal strengths and not on weaknesses. Another pre-condition for a complete happiness is the sense of security about the past, the present and the future. The present moment is the decisive one that must be lived and enjoyed, so it means one has to be 'here and now' which excludes sinking in unpleasant memories about the past, and intends to use internal resources as well as to plan activities that improve the future.

Psychological well-being is a broad concept that includes the experience of pleasant emotions, low levels of negative mood and satisfaction with life (Goldes, 2008).

Psychological well-being can be defined as a person's current evaluation of happiness. This evaluation can be expressed with an emotional expression "I feel good" (Schwartz \& Strack, 1999).

There are two approaches to define the psychological well-being: the hedonistic approach which defines well-being and happiness in terms of pleasure and happiness, and the eudemonistic approach, which focuses on self-realization, expressiveness and the extent to which people are able to fulfill their potential (Waterman, 1993; Ryan \& Deci, 2001).

OPTIMISM [lat. optimus - optimum] is the perception of the world, characterized by joy of life, faith in the future, activities, belief in the value of life, the triumph of good over evil, etc.

Optimism and pessimism are associated with general expectations of a positive or a negative outcome in the future (according to Beck, Weissman, Lester, \& Trexler, 1974; Carver \& Scheier, 1982; Dember, Marti, Hummer, Howe, \& Melton, 1989; Melges \& Bowlby, 1969; Minkoff, Bergman, Beck, 1973; Reker \& Wong, 1985; Scheier \& Carver, 1985; Wenglert \& Rosen, 2000).

Optimists more often predict that good things rather than bad things will happen to them (Scheier \& Carver, 1985).

In earlier research pessimism is defined as despair, but optimism - as a hope. (Minkopf et al, 1973; Beck, et al, 1974).

The definition of optimism / pessimism was expanded, without general expectations of a positive or a negative outcome in the future, including explanations of how the past successes and failures affect future expectations, i.e. based on the past experience the individual is trying to determine the probability of success or failure (Melges \& Bowlby, 1969; Scheier \& Carver, 1985).

Developing the concept of optimism / pessimism concept, it was formulated that any success promotes attempts even when there are obstacles, whereas the result of a permanent failure is abstinence from challenges (Scheier \& Carver, 1985). 
OF PSYCHOLOGY

IN THE $21^{\text {st }}$ CENTURY Volume 2, 2012

60

The well-being is most often associated with positive emotions and sound attitudes (Fredrihson, 2000).

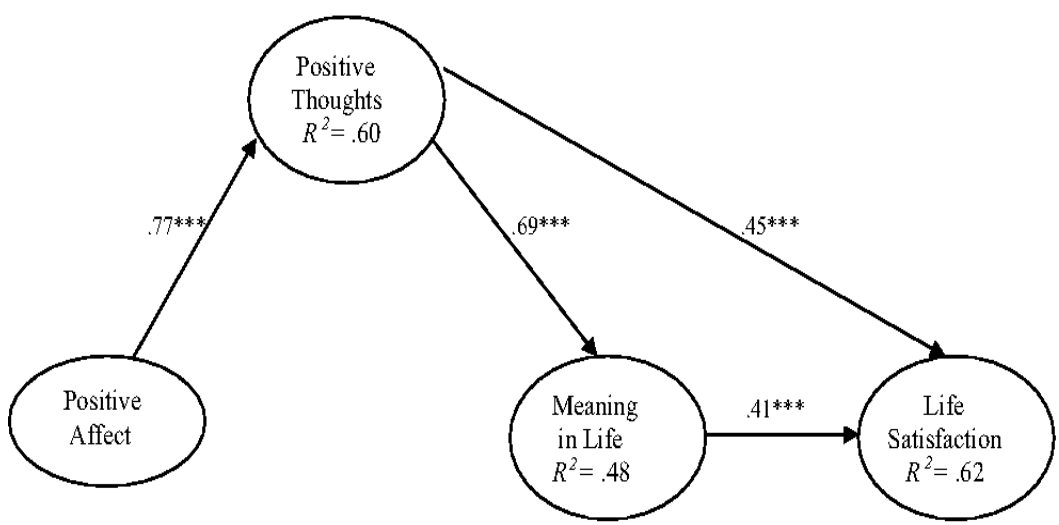

Figure 1: Evaluation of standard parameters of positive emotions: positive thoughts and the meaning of life as an intermediary between the positive effect and satisfaction with life. $* * * p<0.001$.

Positive effects or emotions have an impact on positive thoughts, and positive thoughts have an impact on the meaning of life, which, in its own turn, is related to life satisfaction.

According to the evidence gathered by Fredrihson (2000), positive emotions can in advance tune people to see events in a positive sense; series of studies by other authors proved that positive emotions and positive mood may predispose people to feel that their life has a meaning (King, Hicks, Krull, \& Del Gaiso, 2006).

In case people find themselves in trouble or in difficulty, their experience in diversity of emotions ranges from excitement and eagerness to anger, concern and depression. The balance between these feelings appears in connection with the degree of optimism or pessimism. Even in very difficult situations optimists foresee a positive outcome. Such self-reliance gives the mixture of positive feelings. In contrast, pessimists are more prone to negative emotions, such as anxiety, guilt, anger, sadness as well as despair (Carver \& Scheier, 1998; Scheier \& Carver, 1992; Snyder et al., 1996).

Scientists have studied the effects of optimism on psychological well-being. Some of the researches show that people with a positive view of life tend to be in a better mood and with a greater power of adaptability. As they are more flexible when facing a disaster, they are less affected even in the worst conditions. They respond to the challenges more flexibly and creatively. It is like they are ready to meet difficulties and keep smiling when they appear; moreover, they learn how to face and overcome dangers rather than avoid them. Their vision allows them to work effectively rather than impulsively in a tense situation. They win because they persevere. Their personal relationships are also satisfactory, they are not shy to get help from friends, family, colleagues and the public in case of need. The positive disposition also affects physical health. Pessimistic and depressive people more often experience high blood pressure, their immune system is not effective, and after a surgery they recover slower and with complications. This proves that optimism has a positive effect on the psychological well-being (Goldes, 2008).

As it is apparent from the recent studies, it can be concluded that the most important differences of social structures are predetermined by the level of optimism / pessimism and affect the psychological well-being and physical health; it also means that optimism acts as an intermediary between the social impact on health and psychological well-being. People control their own wellbeing according to their sense of optimism/pessimism.

\section{Results of Research}

The following will describe three examples from the work done by Latvian research group (Golde, Svence, 2008, Bērziņa, Svence, 2012, Gluškova, Svence, 2011)

One of the studies carried out in the Riga Teacher Training and Educational Management Academy was about correlations between well-being and optimism (Svence, Golde, 2008). During 
the study with the help of Caroll D. Ryff's test 'Scales of Psychological Well-Being' and Dr. Martin Seligman's "Attributional Style Questionnaire" 42 people were tested, with the aim to find out the Volume 2, 2012 effect of the level of optimism or pessimism on the individual's psychological well-being.

It can be concluded from the obtained data that there is a correlation between the level of optimism and well-being; the income level is not equal to the level of psychological well-being, as the income rises, people adapt and perceive the new situation as appropriate ; moreover, they may be dissatisfied with the income in the absence of the other factors that influence well-being; apart from that, even a very high materialistic wealth does not ensure a high level of psychological well-being if there is a general dissatisfaction with the life and the level of optimism is low.

Another sample is the research work 'The dynamics of the resilience indicators for a 40-50 year old female in a positive intervention group" by Svence and Berzina in 2012.

The keywords of the research are resilience factors, resilience risk factors, positive intervention.

The task of the research is the theoretical analysis of the latest research resilience factors and resilience risk factors; also, to analyze the theory of the intervention of positive psychology and the development of programs. Based on quantitative methods (narrative content analysis), the content of resilience is discovered and the resilience factor pattern has been created. The authors have created a positive intervention author program 'Resilience skills training'. The program is based on the Penn Resilience Program (Seligman at al, 1999) and Masters Resilience Trainer (Gillham, Reivich, \& Jaycox, 2008 Reivich \& Seligman, 2008) programs which include the vitality of the development of such traits as self-regulation, endurance, optimism, meaningful life as well as character strengths, etc).

The practical aim was to analyze and to compare resilience indicators in the group of 40-50 year old women within the period of twelve weeks by using the program of positive intervention. Women's narrative content analysis proves that women daily stress is caused by various tense situations; as a result, women's psychological well-being is affected; moreover, the stress enhances the resilience risk factors that, in their own turn, cause a human adaptive interference. The narrative content analysis proves that women's resilience is the compilation of the resources, i.e., the vitality of the personality resources which include the force of will, hope, optimism, ability to adapt to changes, stress tolerance, ability to solve problems and decision-making, positive thinking and sound attitude towards oneself and life in general. The women's important resilience factor is the social support of the relatives, which gives strength and comfort, communicating with one another, sharing the previous experience, understanding the resources of resilience, the sense of responsibility, positive attitudes towards themselves, belief in yourself and the desire to improve themselves. After the intervention of quantitative analysis of the results of the study the author concludes that resilience is a set of skills that can be developed. It is proved by the results of the indicators before and after the intervention is received as well as by the results achieved in positive psychology (Seligman et al, 1999; Gillham, Reivich, \& Jaycox, 2008 Reivich \& Seligman, Jackson, \& Watkins, 2004, Khoshaba, Maddi, 1999, Gillham et al. 1991; Reivich, Shatte \& Gillham, 2003). The authors have approbated the program 'Resilience skills training' and have approved Resilience scale (Resilience Scale, RS, Wagnild \& Young, 1993, translated by G. Svence, I.Berzina, 2011) and created a theoretical pattern of the resilience factor.

Another sample is from the research 'Differences of well-being, self-esteem and resilience rates between women of various age groups'.

The research was conducted on the dynamics of resilience during the time when "Krājbanka" (Savings Bank) went bankrupt and several women turned to social service officers for help. Advising female clients, the idea of creating resilience and positive intervention program emerged; also, the idea to examine the connection between cognitive affect concept and parameters of well-being, self-esteem and resilience turned up; apart from that, it also occurred to verify the implication of the concept in different age groups as well as in groups of different education levels, also, among the employed and the unemployed as well as considering the marital status.

The authors confirmed that social support and marriage at times increase the associative psychological well-being, whereas long periods of unemployment are tied with low self-esteem and causes depression. Family support and personality traits as well as the changes of the individual's role have a significant impact on the personality well-being, too. The assessment of self-esteem is related to individual's motivation for various achievements in their own life because the individuals 
OF PSYCHOLOGY

IN THE $21^{\text {st }}$ CENTURY Volume 2, 2012

62

with a higher self-esteem level have a higher motivation, and similarly a lower assessment of selfesteem is related to a lower motivation (Heimpel, Sara A.; Wood, Joanne V.; Marshall, Margaret A.; Brown, Jonathon D., 2002).

Conclusion - resilience or resistance to negative events must be assessed together with the personality traits of "courage and "achievement motivation" to deal with the influence of negative factors, which coincides with the studies by Maddi (2005). The courage and motivation creates the ability to deal with the problem rather than to avoid it, and to learn how to cooperate with others by giving and receiving help and encouragement. Thus, strength of personality becomes a model of attitude and behavior that helps to convert the effects of negative factors and stress, and to protect oneself form potential disaster, facilitating the opportunity of growth.

Positive emotions in the process of stress have a functional role in a development of resilience. Individuals that are remarkably resilient have the ability and experience to cope with the stress quickly and efficiently. Studies have shown that such people use positive emotions to beat back negative feelings in one-selves and to find positive meaning in stressful situations, perceiving them as a lesson rather than a catastrophe. This means that positive emotions help to get rid of negative emotions and anxiety caused by tense situations (Tugade, Michele M.; Fredrickson, Barbara L., 2004).

In other studies psychological flexibility or resilience has been described as the ability to get rid of negative emotional experiences, developing the ability to adapt to stress conditions with a greater flexibility (J. H. Block \& Block, 1980; J. Block \& Kremen, 1996; Lazarus, 1993).

Several studies have described personality, full of resilience, i.e., being optimistic, curious, willing to meet new challenges, with a distinct positive emotionality (J. Block \& Kremen, 1996; Klohnen, 1996). Such people are able to develop purposefully their positive emotionality using humor (Werner \& Smith, 1992), relaxation techniques (Demos, 1989; Wolin \& Wolin, 1993) and optimistic thinking (Kumpfer, 1999). Consequently, the positive emotionality can be evaluated as an important and integral composite element of the resilience.

It was found that 40-60 year old women with higher education, marital status "unmarried", employed, with a high self-esteem and childless have higher resilience indicators.

\section{Discussion}

From the first sample:

1. There is a correlation between psychological well-being and the level of optimism.

2. If in other global studies income level does not correlate with psychological well-being, in Latvian sample there is the trend of the level correlation.

From the second sample:

1. After the theoretical and quantitative analysis of the results of the study it can be concluded that the research question as to whether there are differences in women's psychological well- being in the age group of 40-50 before and after the resilience intervention, the measurement results of vitality, life satisfaction, stress management strategies, indicators of depression, and well-being indicators, gained a positive answer, because, according to the test and survey measurements, the authors have found that all members of the group after the positive resilience intervention have higher well-being indicators in the results of the questionnaire of C. Ryff (Scales of Psychological Well-Being, Ryff, 1989).

2. Comparing the obtained results before and after the intervention, it can be confirmed that the resilience levels of the participants, although marginally, have increased. It should be taken into account that resilience includes living habits, attitudes, feelings, communication styles, responses to emergencies, which have been formed for decades.

On the basis of the results of the applied intervention the research as well as the metaanalysis of the theory of resilience it can be concluded that resilience is not an inherited quality; it is a skill that can be improved by developing the cognitive skills (positive thinking rather than catastrophic thinking) and by emphasizing personal strengths, i.e., self-esteem as well as accomplishments. Another evidence of that, according to the research results, 
are changes in additional mixed variables (depression, stress management, psychological well-being, and life satisfaction) after the intervention, which is consistent with the results obtained by the other research authors in positive psychology in programs of resilience development: Penn Resilience Program - PRP (Seligman et al, 1999), Master Resilience Trainer MRT. (Gillham, Reivich, \& Jaycox, 2008 Reivich \& Seligman), Adaptive Learning Systems - ALS (Jackson \& Watkin, 2004), Hardiness Training (Khoshaba, Maddi, 1999), Achieving Personal Excellence - APEX (Gillham et al., 1991; Reivich, Shatte \& Gillham, 2003).

From the third sample:

1. Women with a lower education have a lower assessment of psychological well-being than women with the higher education, and it corresponds to the average low or nearly a poor level. The levels of the psychological well-being of women with the higher education correspond to the average high rating.

2. Comparing women's employment status, the indicators of psychological well-being and self-esteem differ insignificantly, i.e., the employed women have higher well-being and self-esteem rates than the unemployed women.

3. The unemployed women have a lower assessment within the scale of life span and space management and positive relationships with others, corresponding to an average low.

4. From the results of the survey of psychological well-being and the assessment of selfesteem, comparing women with children and childless women, it can be concluded that the birth of a child and the number of children does not affect psychological well-being and self-esteem.

5. According to the results of the Rosenberg's Self-esteem Scale, simple average of selfesteem of the entire sample of women can be assessed as medium high or above average, which is the evidence of a moderately high activity in communication and self-esteem.

6. The lowest level of education corresponds to the lowest assessment of self-esteem, while for women with the higher education the assessment of self-esteem is the highest. Thus, it can be concluded that the women with the higher education have also higher self-esteem rates than the women with a lower education level.

7. For the women with the primary and secondary education, as well as with the unfinished higher education, the rates of self-esteem are average, but for the women with the completed secondary vocational and higher education the rates of self-esteem are higher and correspond to the high or nearly the high level.

8. The relationship status and the marital status change the rates of self-esteem insignificantly, and in all cases the women's rates correspond to the high self-esteem assessment.

9. The assessment of self-esteem of the employed women is high, but that of the unemployed women it is average, which means that the employed women have a higher self-esteem than the unemployed women.

10. There are no statistically significant differences in rates between self-esteem and psychological well-being in general, and there are no statistically significant differences in self-esteem rates of women of various age groups.

11. Women with the lower rates of self-esteem have lower resilience questionnaire results in comparison with the women with higher self-esteem rates. The analysis of the Pearson's correlation confirms that there is a correlation between the resilience and the self-esteem assessment.

12. The resilience rates for women with the higher education are higher than for the women with lower education levels.

13. There is a higher average rating of resilience for the employed women.

14. The unmarried women's resilience level is higher than that of the other respondents.

15. The resilience rates of the childless women are higher than those of the women with children. 
OF PSYCHOLOGY

IN THE $21^{\text {st }}$ CENTURY Volume 2, 2012

64

16. The women's age does not impact the self-esteem and psychological well-being rates.

17. There is an interconnection between the self-esteem and psychological well-being survey results.

18. There is a correlation between the resilience and self-esteem assessment.

19. The Pearson correlation analysis shows the link between self-esteem, resilience and wellbeing rates for the women of different ages, thereby the research hypothesis is confirmed, and there is a correlation among the self-esteem, resilience and well-being rates for the women in various age groups.

\section{Conclusions}

The information obtained from the research as well as the survey results show that well-being indicators, i.e., positive thinking, optimism, satisfaction, lower rates of depression, self-esteem and the stress tolerance in life are psychological phenomena that can be evolved by using specific cognitive and personality development approaches. It is crucial to take into account the specific features of the people's age, their educational background, their marital status as well as their employment status when compiling intervention programs.

Up to now psychology in Latvia primary focused on nationally supported violence intervention programs. It is high time to introduce resilience intervention programs based on positive psychology that first and foremost facilitates to change the processes of thinking, to develop sound attitudes as well as the awareness of the individual's resources.

\section{References}

Bonanno, G., Bucciareli, V. (2007). What predicts psychological resilience after disaster? The role of demographics, resources, and life stress. Journal of Consulting and Clinical Psychology, 75 (5), 671-682.

Bonanno, Galea (2004). Loss, Trauma, and Human Resilience: Have We Underestimated the Human Capacity to Thrive After Extremely Aversive Events? American Psychologist, 59 (1), 20-28.

Cohn, M. A., Fredrickson, B. L., Brown, S. L. (2009). Happiness Unpacked: Positive Emotions Increase Life Satisfaction by Building Resilience [article). Retrieved from PsycNet database (APA org).

Diehl, M., Hay, E. L. (2010). Risk and Resilience Factors in Coping with Daily Stress in Adulthood: The Role of Age, Self-Concept Incoherence, and Personal Control. Developmental Psychology, American Psychological Association, 5, 278-292.

Fredrickson, B. L., Cohn, M. A., Brown, S. L. (2009). Happiness Unpacked: Positive Emotions Increase Life Satisfaction by Building Resilience. Mikels J. A. In Emotions, American Psychological Association, 9,3,361-368). Retrieved on 20 March 2012, from http://www.unc.edu/peplab/publications/Cohn_Fredrickson_et_al_2009.pdf

Jackson, \& Watkin (2004). The resilience inventory: Seven essential skills for overcoming life's obstacles and determining happiness. Selection \& Development Review, 20, 6.

Lord, J. H., O’Brien, K. Ed. (2007). Developing resilience. National Victim Assistance Academy, 5. Retrieved from PsycNet database (APA org.

Kernis, M. H., Cornell, D. P. Sun, Chien-Ru, Berry, A. Harlow, T. (1993). There is more to self-esteem than whether it is high or low: The importance of stability of self-esteem. Journal of Personality and Social Psychology, 65, (6), 1190-1204.

Keyes, C. L. M. (1998). Social well-being. Social Psychology Quarterly, 61, 121-140.

Kumpfer, K. L. (1999). Factors and processes contributing to resilience: The resilience framework. In: Glantz, M.D, Johnson, J.L, (ed). Resilience and development: Positive life adaptations. New York: Kluwer Academic/Plenum Publishers (pp.179-224). Retrieved from PsycNet database (APA org).

Lazarus, R. S. (1993). From psychological stress to the emotions: A history of changing outlooks. Annual Review of Psychology, 44, 1-21.

Svence, G. (2009). Pozitīvā psihologija (Engl. positive psychology) [Monograph]. Riga: Zvaigzne ABS, Latvia. 
Svence, G. (2009). Ievads Latvijas psiholoğijas vēsturēe (Engl. introduction in history of Latvian psychology)

[Monograph]. Riga: RAKA, Latvia.

Riga Teacher Training and Education Management academy. (2008, 2009, 2010, 2012). In Svence, G. (Eds). Master theses in psychology. Authors: Golde, 2008, Andermane, 2009, Andermane, 2010, Bērziņa, 2012, Gluškova, 2012), Riga, Latvia.

Advised by Irakli Imedadze, Uznadze Institute of Psychology, Georgia

Received: February 21, 2012

Accepted: March 12, 2012 